\title{
Exploring strategies for promoting trauma-informed care and reducing burnout in acute care psychiatric nursing
}

\author{
Donna M. Wampole*1, Sara K. Bressi ${ }^{2}$ \\ ${ }^{1}$ School of Social Work, University of Southern Maine, United States \\ ${ }^{2}$ Graduate School of Social Work and Social Research, Bryn Mawr College, United States
}

Received: September 24, 2018

DOI: $10.5430 /$ jnep.v9n5p110

\author{
Accepted: January 16, 2019 \\ Online Published: January 26, 2019 \\ URL: https://doi.org/10.5430/jnep.v9n5p110
}

\begin{abstract}
Psychiatric nurses in inpatient settings provide person-centered and relationship-based care to persons in acute distress from behavioral health and substance use problems. The emotional labor of this highly interpersonal care is further complicated by the high rates of historical trauma among this population. This article summarizes the impact of trauma on patients in acute psychiatric settings, the impact of challenging organizational contexts and patient distress on nurse burnout, and proposes four strategies for promoting trauma-informed care by inpatient psychiatric nurses including a) promoting education of nurses on the impacts of trauma, b) building support among nurse colleagues, c) emphasizing clinical skills in coping with patient distress, and d) implementing mindfulness skills as a core coping strategy for nurses for managing their reactions to patient distress. Trauma-inforced care holds patient safety as primary to clinical effectiveness and is also crucial for promoting supportive patient-nurse relationships. As such, trauma-informed care has the potential to combat nurse burnout and improve outcomes for patients.
\end{abstract}

Key Words: Trauma-informed care, Nurse burnout, Acute care, Psychiatric nursing

\section{INTRODUCTION}

Inpatient psychiatric nurses, as part of an interdisciplinary team of clinicians, typically have the most direct contact with patients and are tasked with monitoring patients' progress in treatment, dosing medications, coordinating care with doctors and social workers, and in some contexts facilitating psychoeducational group treatment with patients. A position statement from the American Association of Psychiatric Nursing (APNA) ${ }^{[1]}$ supported by a recent systematic review of the literature examining person-centered care in psychiatric nursing ${ }^{[2]}$ outlines that these nurses are expected to pro- vide recovery-oriented relationship-based patient care. The relationship between psychiatric nurses and patients has been characterized as highly interpersonal and dependent on trust and as such may require significant emotional labor. ${ }^{[3]}$ This care is embedded in organizational contexts often characterized by numerous workplace stressors including high patient to nurse ratios and time pressure related to administrative tasks. $^{[4]}$

As noted, the relational quality of treating persons with psychiatric disorders with acute needs may be interpersonally demanding and requires well-developed communication

\footnotetext{
${ }^{*}$ Correspondence: Donna M. Wampole; Email: donna.wampole@maine.edu; Address: School of Social Work, University of Southern Maine, Masterton Hall, 71 Bedford St. Portland, ME 04104, United States.
} 
skills. ${ }^{[5]}$ Persons with psychiatric disorders admitted to inpatient facilities often experience the most intense symptoms including suicidality, affect and mood dysregulation, psychosis, and the psychological and physical effects of dependence on or abuse of psychoactive substances. Relatedly, psychiatric nurses have reported higher incidences of managing patient and family complaints and elevated rates of verbal abuse when compared to other hospital nurses. ${ }^{[4]}$

Potentially adding to the emotional labor required by inpatient psychiatric nursing is a growing recognition that a significant proportion of persons with behavioral health problems have histories of trauma. ${ }^{[4,6-10]}$ The Substance Abuse Mental Health Services Administration (SAMHSA) ${ }^{[11]}$ defines trauma as "an event, series of events, or set of circumstances that is experienced by an individual as physically or emotionally harmful or life threatening and that has lasting adverse effects on the individual's functioning and mental, physical, social, emotional, or spiritual well-being". Persons with a history of trauma often experience emotional dysregulation, crisis management difficulties, self harm, and other acute symptoms. ${ }^{[12,13]}$ Furthermore, the constraint of a psychiatric unit while an attempt to promote safety in a least restrictive environment may provoke patients with trauma histories to feel trapped, coerced, or in danger and as such, in the context of an acute episode of mental illness, elicit strong emotional dysregulation and fear. ${ }^{[14]}$ Unfortunately, while patients are brought to inpatient care to promote safety, they may also feel incredibly emotionally and physically unsafe in this context. As such, it follows that inpatient units may also feel unsafe for nurses. The severity and intensity of patient symptoms creates a multitude of interpersonal challenges between patients and nurses, between nurses and families, as well as between nurse colleagues.

This chronic interpersonal stress in combination with organizational stressors may intensify the risk for nurse burnout. The term "burn-out" was first utilized in 1974 by Herbert Freudenberger ${ }^{[15]}$ in his reflections on the symptoms displayed by workers in various fields who were placed in contexts with ongoing exposure to stress. He described burnout as an experience of physical and behavioral symptoms linked to stressors at a job site, beginning at least one year into service. Physical symptoms of burnout included fatigue, exhaustion, and chronic medical disruptions such as headaches and gastrointestinal issues. Burnout also included behavioral symptoms such as acting out at the job site in anger or sadness.

In their studies of work-related burnout for helping professionals, Maslach and Jackson ${ }^{[16]}$ define burnout utilizing three main concepts, namely emotional exhaustion, deper- sonalization, and reduced personal accomplishment. Emotional exhaustion references feeling emotionally depleted or empty, depersonalization references feeling withdrawn or emotionally removed from patients and reduced personal accomplishment encompasses viewing one's work as subpar as compared to prior work. ${ }^{[17]}$

Burnout may directly loop back to patient care and safety in placing nurses at risk for diminished efficacy on the job, negative othering of the patient group, decreased ability to promote safety on the unit, or departure from the workplace. ${ }^{[18]}$ In 2016, a survey ${ }^{[19]}$ of 138 hospital facilities reported that behavioral health units reported the highest rate of nurse turnover. These workforce concerns cost the health system in their impact on the efficacy of staff, increased training costs, and poor patient care. As noted in psychiatric nursing, burnout on the job likely emerges partially in response to interpersonal challenges with patients with significant trauma histories, and the embeddedness of these interactions in a work environment that is under resourced. ${ }^{[4,20-24]}$ Furthermore, burnout is also rooted in organizational contexts that fail to provide structural support for nurses to process daily exposure to victimization and trauma.

A movement towards offering psychiatric care that is traumainformed recognizes that patients must feel safe in order to fully benefit from treatment. As defined by SAMSHA, ${ }^{[11]}$ trauma-informed care understands the scope of trauma among vulnerable persons, recognizes the outcomes of trauma, and integrates this knowledge of trauma into direct patient care, policies and systems in an effort to also actively resist re-traumatizing the client group. In her foundational work in the field of defining and examining trauma, Judith Herman $^{[25]}$ reports that survivors of trauma are challenged with modulating intense emotions such as anger or profound sadness, and become severely intolerant of the intense emotions or reactions of others. Additionally, Herman ${ }^{[25]}$ notes that survivors, while experiencing, "profound disruption in basic trust", also display an intense need for relationships that foster and ensure trust and protection (pg. 56). A traumainformed care (TIC) approach to practice cautions against pejorative interpretations of these symptoms and recognizes that these patient presentations occur not out of choice, for attention-seeking or defiance, but out of a developed set of unconscious and conscious strategies to regain control in response to the patterned invalidation, chaos, and betrayal of complex trauma. ${ }^{[26]}$

An emerging emphasis on the importance of TIC brings attention to the impact of the high levels of distress among particular populations on staff, their job satisfaction, and work-related stress. ${ }^{[27]}$ TIC highlights that these behaviors 
and difficulties in coping with distress develop in the context of survival in abusive environments, and inevitably directly impact the experience of psychiatric nurses and other professionals working with these patients and potentially expose clinicians to vicarious trauma and subsequent similar problems in regulating distress. ${ }^{[28]}$ In other words, organizations and health systems must "integrate an understanding that the experience of traumatic events impacts all people involved". ${ }^{[11]}$ A TIC approach to psychiatric care notes that clinicians also need to feel safe to have the emotional labor of the work recognized and processed in order to prevent the hallmarks of burnout. Staff burnout precludes the delivery of TIC, but TIC may prevent nurse burnout.

As such, this paper summarizes and reflects on key literature relevant to acute psychiatric nursing and presents four key strategies aimed at promoting TIC among psychiatric nurses in acute care. These strategies may be helpful in reducing the effects of patient distress on psychiatric nurses thus ameliorating nurse burnout. From a patient-safety focused care approach, the first three strategies maximize nurses' ability to promote trust and safety in their relationships with patients. In addition, reflecting on the literature of the benefits of mindfulness, a fourth strategy proposes the benefits of this practice for nurse wellbeing.

\section{Strategy \#1: Train and educate NURSES ON THE IMPACT OF TRAUMA}

As outlined by the principles of TIC, it is imperative that psychiatric nurses have education in the nature and impact of trauma on patients. ${ }^{[29]}$ Education may assist nurses in identifying symptoms of trauma (i.e. trauma cueing) as well as aid nurses in promoting healthy decision making which may assist clients to feel safe. First, education that emphasizes the etiology and effects of trauma is paramount. In a recent literature review, Muskett ${ }^{[30]}$ reflects that education and promotion of staff competency in the principles of TIC were core to an agency culture valuing TIC and patient-centered recovery. SAMHSA and other allied organizations ${ }^{[31]}$ all note the importance of reinforcing through continual education the understanding by staff of the effects of childhood trauma on adult mental health pathology. Many studies examined by Muskett ${ }^{[30]}$ utilized TIC education from the beginning of one's career on an inpatient unit through time focusing on multiple areas including the trauma needs of those with substance abuse disorders, establishment and termination of therapeutic boundaries, and consumer empowerment.

Additionally, education regarding trauma is noted to assist mental health nurses relate to consumers and improve the therapeutic relationship. ${ }^{[32,33]}$ Compared to units without a trauma-informed lens, those offering TIC included education to nurses focused on trauma and how trauma leads to often called maladaptive behaviors which historically have been viewed as simply bad patient behavior. By educating nurses on the effects of trauma, patient actions can be assessed as reflective of trauma cues, such as loss of control or loss of patient voice leading to an opportunity to enhance nurse-patient communication for de-escalation. Wilson and colleagues ${ }^{[32]}$ suggest, that while education is fundamental, agencies employing TIC must also embrace it on a system level including managerial and system-wide buy-in. Nurses cannot be educated in TIC if an agency itself has not embraced it. All members of an inpatient unit, preferably the entire facility, needs TIC education to assist one another in understanding patient interactions as well as staff interactions.

Education in TIC in inpatient psychiatric care is important especially in the use of techniques to assist patients in deescalation in an effort to eliminate the use of seclusion and restraints which often injure or re-traumatize patients. Seclusion involves the movement of a patient to a solitary environment while restraint involves manual or instrumental maneuvering to obtain physical control of a patient. While these techniques have been used for decades, individuals on whom restraints and seclusion are placed are cued to past periods of abuse or neglect, and thus re-traumatized. Use of seclusion and restraint may have a paradoxical effect and lead to a resurgence of the problematic behaviors. As part of TIC, education needs to include the understanding of the effects of seclusion and restraint as cues to re-traumatization as well as training in additional non-traumatizing techniques to improve patient behaviors and make inpatient milieus more manageable for staff. ${ }^{[34-36]}$ This aim was highlighted in 2005 by the National Association of State Mental Health Program Directors (NASMHPD) ${ }^{[31]}$ who established six principles for reducing use of seclusion and restraint. In particular, the third principle recognized the importance of workforce development and highlighted the need for ongoing staff education regarding trauma, restraint, and the prevention of re-traumatization. In their 2011 study which examined the outcomes of implementation of the NASMHPD principles, Azeem and colleagues ${ }^{[37]}$ noted a markedly downward trend in the use of both seclusion and restraint in a long-term child and adolescent facility following implementation. In this facility, education regarding the effects of trauma were offered as part of the orientation for new hires, continuing education was provided routinely at staff meetings and trainings, and assessment of knowledge was added to regular performance evaluations. The study notes that following implementation of the NASMHPD principles, the trend in restraint and seclusion use dropped quickly in the first six months of the study 
and with the exception of one quarter, maintained reduction for the nearly three-year retrospective study.

Education regarding trauma and its impact, or on skills for patient de-escalation, not only benefit patient safety, and prevent re-traumatization, it also reduces patient trauma cueing, and lessens the interpersonal impact on nurses. While limited data currently exists reflecting upon mental health nurse experience with TIC education, what is known cites positive experiences for nurses. ${ }^{[35]}$

\section{Strategy \#2: BuIld SOCIAL SUPPORT AMONG STAFF}

TIC requires that helpers support each other on the job to avoid becoming overwhelmed by constant exposure to traumatic material and the outcomes of trauma. The care and nurturance of staff is thus a core aspect of an organization maintaining the capacity to hold the difficulties of trauma wounds. This has been carefully implemented in treatment models such as the Sanctuary Model, an evidence-based framework for organizations that treat trauma victims. ${ }^{[38]}$

In nursing, the relationships between and among nurse coworkers are important for managing on-the-job stress. Prior studies link the experience of nurse burnout to interpersonal challenges experienced between nurse colleagues. ${ }^{[39-43]}$ In their study utilizing qualitative analytical interviews with registered nurses who had already chosen to leave their profession, MacKusick and Minick, ${ }^{[41]}$ describe several incidences of horizontal harassment (as termed by researchers) in which nurses staffed to be working together often were at odds, or worse, defending against provocation and harassment from one another.

Relatedly, Happell and colleagues, ${ }^{[39]}$ examined the management of stress between general psychiatric nurses and those employed on a forensic psychiatric unit. Originally posited to have higher scores for burnout of the two units, the forensic study group reported stronger positive perceptions of their work environment including stronger involvement in decision making and unit support, which was correlated with lower burnout measurement scores. This study in particular points to the benefits that nurses who work together in supportive ways assist one another in identifying and addressing perceived stress and burnout.

Going beyond the focus of intra-nurse relations, Van Bogaaert and colleagues ${ }^{[44]}$ focused on nursing care practice environments and their relation to the experience of burnout in mental health nurses, and nurse perceptions on patient quality of care. The study focused on the relational exchange between nurses and physicians, nurses and management systems, and nurses and the overall healthcare organization as correlations to self-reported burnout factors followed by how those relations and ensuing burnout factors affected nurses' perception of patient care. The multivariate analysis noted overall that positive ratings of nurse practice environments, including management and inter-professional relations resulted in positive nursing views of patient outcomes and reduced burnout factors. These studies draw focus on the need for positive nurse relations and support as a target for implementing TIC and improving patient experience and safety.

In examining points of Workforce Development, the NASMHPD $^{[31]}$ assessed how facilities addressed staff empowerment issues and if facilities promoted employee empowerment at all. They specifically questioned if staff members were allowed to swap assignments when needed or flex their schedules. The combination of healthy communication and flexibility when available can promote healthy nurse relations and team building. Units and hospitals that promote open and constructive communication between nurses, nurses and other staff, and management with nurses can lessen nurse burnout while creating safer, more supportive patient care. Likewise, units that promote flexibility can assist nurses in attending to personal needs to prevent burnout from occurring. ${ }^{[45]}$ TIC gives light to the challenges nurses face in relation to patients and staff and acknowledges that the daily interaction on a closed unit can lead to nurse distress. TIC also acknowledges that this exposure may highlight a nurse's own traumatic past experience leading to her/his own re-traumatization ${ }^{[35,38]}$ and so improving nurse experiences with and beyond patient interactions including the use of healthy, open communication, flexibility, and support can assist in nurse wellbeing, reduce burnout and promote TIC.

\section{Strategy \#3: EMPhasize The DEVEL- OPMENT OF CLINICAL SKILLS FOR MAN- AGING AND PROCESSING PATIENT DIS- TRESS}

In order to examine the importance of TIC in the field of nursing, one must also examine the element of "relationship", in nursing. While the relationship is of importance in all nursing fields, it is most critical in psychiatric nursing as one is attending not just to a trauma of the body, but of the mind. Patients experiencing mental distress require a level of care attuned to presence, energy, voice inflection, and affect as much as medical knowledge and skills. ${ }^{[46]}$ From this standpoint, nursing can be viewed from a relational lens where nurses are in ongoing dyads of communication and reflection with patients.

Other mental health clinicians are trained in the concept of 
countertransference and so are aware that distress, anger, anxiety, or sadness experienced by the clinician may in fact be a communication of the patient's internal state or experience. ${ }^{[22]}$ Countertransference involves thoughts, fantasies, and feelings a professional may experience in interactions with a patient. Countertransference relates not only to the client but to the shared relationship between client and professional and is one of the most important sources of information for understanding a patient's experience. ${ }^{[22]}$ When a professional can tune-in to her own internal perceptions of a client interaction, she can learn where a patient's point of view and importantly, history of expectations or needs of others comes from. Despite being an integral part of a mental health treatment team, most nurses receive limited training on relational dynamic elements like transference or countertransference, as education is focused on medical modalities. ${ }^{[47]}$ For nurses, a lack of education and understanding of the countertransferential process may lead to negative conceptualizations of patients and negative relationships ${ }^{[48]}$ As such, it is possible that when nurses experience these interpersonal stressors at work, they may unwittingly start to attribute them to the patients being difficult or deficient in some way. Coupled with work stress, this creates depersonalization, and thus decreases the nurses' effectiveness to intervene with clients in a trauma-informed way. ${ }^{[49]}$

Studies focused on patient safety in the psychiatric field have involved examination of how patient safety is defined beyond typical concerns of falls, infection, and medication errors in encompassing the importance of interpersonal safety. Berg and colleagues ${ }^{[50]}$ learned that psychiatric patients experiencing suicidal emotions while hospitalized report three factors; connection, the knowing someone cares and confirms the patient's feelings; protection, the receipt of support from a caretaker; and control, which includes the insight a patient gains regarding her/his suicidality as she/he moves toward discharge, as primary features of their perceived safety with staff. One can posit that nurses not attuned to communication and countertransferential experiences can struggle reaching patients in these experiences of safety. Cutcliffe and colleagues, ${ }^{[51]}$ noted suicidal patients receiving inpatient care seek "reconnection with humanity", which is primarily provided through the care and communication with nurses. Nurses attuned to the patient feel less depersonalization and present as the first step for patients in their reconnection to humanity and experience of interpersonal emotional safety.

As patients experience an increase in feelings of connections and trust with nurses they are learning recovery skills to use post-hospitalization. Psychiatric units functioning under TIC recognize that inpatient units need to be facilities focused on recovery, not just stabilization from crises and nurses are in the position of educators for long-term care goals. As Wilson and colleagues ${ }^{[32]}$ note, most non-TIC inpatient facilities limit the topic of ongoing wellbeing in reference to a patient's discharge, not throughout care. By integrating TIC with its focus on staff-patient relationships, nurses can join with their patients in developing and modeling skills of self-regulation, interpersonal effectiveness, and emotion regulation that not only benefit the nurse-patient relationship in the moment but also build the patient's skills for long term recovery. When a patient feels connected to a nurse, trust builds and an opportunity for education on communication and recovery-oriented skills is born.

\section{Strategy \#4: Promote mindfulness- BASED INTERVENTIONS FOR INPATIENT PSYCHIATRIC NURSES}

Mindfulness techniques are skills wherein individuals draw attention to the here and now while also recognizing the ability to let go of distress and situations beyond one's control. While the concept of mindfulness and forms of contemplative practices predate modern medicine and have been part of several religious and spiritual traditions for centuries, recent research from the past two decades have shown it to be of benefit for affect regulation and distress tolerance for individuals in a variety of contexts. ${ }^{[52-54]}$ In her work developing Dialectical Behavior Therapy, Linehan and colleagues ${ }^{[55]}$ focused on the benefits of mindfulness, which they labeled Core Mindfulness, as the backbone of the model. The skills of Core Mindfulness focus on turning one's attention to the here and now and identifying the emotions and thoughts leading to behaviors. The intervention makes direct attempts to impart a strategy for regulating distress and affect.

Mindfulness is now being examined in regards to its benefits to preventing and mitigating stress and burnout in multiple healthcare careers, and thus may be useful tool also for promoting TIC. Goodman and Schorling ${ }^{[56]}$ note that a course in mindfulness has been shown to reduce depersonalization and emotional exhaustion in general healthcare workers as well as a benefit in increasing workers' perception of personal accomplishment, a mitigating factor of burnout. In their 2015 research of mindfulness, burnout, and resiliency of Spanish physicians, Montero-Martin ${ }^{[57]}$ and colleagues note that the use of mindfulness practices may be helpful in altering negative affect states, thereby increasing physician's resiliency to burnout and perceptions of work overload. Guillaumie, Boiral and Champagne ${ }^{[58]}$ noted in qualitative mindfulness studies with nurses that participants reported mindfulness skills increased a personal state of calm at work, as well as an ability to feel greater compassion thereby having improved communication with patients and colleagues. Furthermore, 
nurses reported finding mindfulness helpful for increasing attention to tasks and patients in the moment, lending to an environment of increased patient safety. Additionally, as mindfulness is a skill useful in assisting an individual to note her or his own affect dysregulation, it may lend to the ability to notice both the distress within the practitioner (the psychiatric nurse) as well as within the patient, leading to a greater ability to engage in effective relational attunement.

\section{FINAL REMARKS}

Given the risks for general nurse burnout and the primary focus of psychiatric nursing as both a medical and interpersonal science focused on intense patient-provider interaction, it is imperative that future research be undertaken to expand the understanding of the prevalence and impact of psychi- atric nurse burnout and its relationship to implementing TIC. However, implementation of the proposed strategies for TIC in inpatient psychiatric settings, may aid nurses in developing a better understanding of the vulnerability of patients to re-traumatization and its relationship to challenging patient behaviors, the importance of supportive staff relationships, assist the development of more therapeutic interpersonal relationships between nurses and patients, and promote the use of self-regulatory capacities in coping with vicarious trauma. By integrating TIC into inpatient psychiatric settings nurses can increase their ability to care for themselves while caring for others, and lead by example how recovery is possible for all.

\section{CONFlicts OF INTEREST Disclosure}

The authors declare that there is no conflict of interest.

\section{REFERENCES}

[1] APNA. Position Statement: Staffing Inpatient Psychiatric Units. J Am Psychiatr Nurses Assoc. 2012; 18(1): 16-22. PMid:22344589 https://doi.org/10.1177/1078390311432133

[2] Gabrielsson S, Sävenstedt S, Zingmark K. Person-centred care: clarifying the concept in the context of inpatient psychiatry. Scand J Caring Sci. 2015; 29(3): 555-562. PMid:25377095 https ://doi. org/10.1111/scs.12189

[3] Moreno-Poyato AR, Montesó-Curto P, Delgado-Hito P, et al. The Therapeutic Relationship in Inpatient Psychiatric Care: A Narrative Review of the Perspective of Nurses and Patients. Arch Psychiatr Nurs. 2016; 30(6): 782-787. PMid:27888975 https://doi.org/ $10.1016 / j$. apnu. 2016.03.001

[4] Hanrahan NP, Aiken LH, McClaine L, et al. Relationship between Psychiatric Nurse Work Environments and Nurse Burnout in Acute Care General Hospitals. Issues Ment Health Nurs. 2010; 31(3): 198207. PMid:20144031 https://doi.org/10.3109/0161284090 3200068

[5] Cleary M, Hunt GE, Horsfall J, et al. Nurse-Patient Interaction in Acute Adult Inpatient Mental Health Units: a Review and Synthesis of Qualitative Studies. Issues Ment Health Nurs. 2012; 33(2): 6679. PMid:22273340 https://doi .org/10.3109/01612840.201 1.622428

[6] Batelaan N. Childhood trauma predicts onset and recurrence of depression, and comorbid anxiety and depressive disorders. Evid Based Ment Health. 2016; 19(3): e18-e18. PMid:27091944 https : //doi.org/10.1136/eb-2015-102106

[7] Lee M-A, Kim E. Influences of Hospital Nurses' perceived reciprocity and Emotional Labor on Quality of Nursing Service and Intent to Leave. J Korean Acad Nurs. 2016; 46: 364. PMid:27411764 https://doi.org/10.4040/jkan.2016.46.3.364

[8] Li XB, Li QY, Liu JT, et al. Childhood trauma associates with clinical features of schizophrenia in a sample of Chinese inpatients. Psychiatry Res. 2015; 228.

[9] Celik FH, Hocaoglu C. Implications of childhood trauma on deliberate self-harm in patients with major depression. Klin Psikofarmakol Bul Istanb. 2015; 25: S38-S39.

Published by Sciedu Press
[10] Zanarini MC, Gunderson JG, Marino MF, et al. Childhood experiences of borderline patients. Compr Psychiatry. 1989; 30(1): 18-25. https ://doi .org/10.1016/0010-440X (89) 90114-4

[11] SAMHSA's Concept of Trauma and Guidance for a Trauma-Informed Approach SAMHSA. Available from: https://store.samhsa.g ov/product/SAMHSA-s-Concept-of-Trauma-and-Guidanc e-for-a-Trauma-Informed-Approach/SMA14-4884

[12] Bryant RA, Panasetis P. Panic symptoms during trauma and acute stress disorder. Behav Res Ther. 2001; 39(8): 961-966. https: //doi.org/10.1016/S0005-7967(00)00086-3

[13] Ehring T, Quack D. Emotion Regulation Difficulties in Trauma Survivors: The Role of Trauma Type and PTSD Symptom Severity. Behav Ther. 2010; 41(4): 587-598. PMid:21035621 https: //doi.org/10.1016/j. beth.2010.04.004

[14] Georgieva I, Mulder CL, Whittington R. Evaluation of behavioral changes and subjective distress after exposure to coercive inpatient interventions. BMC Psychiatry. 2012; 12(1): 54. PMid:22647058 https://doi.org/10.1186/1471-244X-12-54

[15] Freudenberger HJ. Staff Burn-Out. J Soc Issues. 1974; 30(1): 159-165. https://doi.org/10.1111/j.1540-4560.1974.tb0 0706. $\mathrm{x}$

[16] Maslach C, Jackson SE. The measurement of experienced burnout. J Organ Behav. 1981; 2(2): 99-113. https://doi .org/10.1002/ job. 4030020205

[17] Maslach C, Schaufeli W, Leiter MP. Job burnout. Annu Rev Psychol 2001; 52: 397-422. PMid:11148311 https://doi.org/10.1146/ annurev.psych.52.1.397

[18] Howard V, Holmshaw J. Inpatient staff perceptions in providing care to individuals with co-occurring mental health problems and illicit substance use. J Psychiatr Ment Health Nurs. 2010; 17(10): 862-872. PMid:21078001 https://doi .org/10.1111/j.1365-2850.20 $10.01620 . x$

[19] Retention Institute. Available from: http://www.nsinursingso lutions.com/administrators/admin-research/retentio ninstitute. aspx Accessed September 18, 2018.

[20] Bowers L, Flood C. Nurse staffing, bed numbers and the cost of acute psychiatric inpatient care in England. J Psychiatr Ment Health Nurs. 
2008; 15(8): 630-637. PMid:18803736 https://doi.org/10.1 $111 / j .1365-2850.2008 .01280 . x$

[21] Ohnishi K, Ohgushi Y, Nakano M, et al. Moral distress experienced by psychiatric nurses in Japan. Nurs Ethics. 2010; 17(6): 726-740. PMid:21097971 https://doi.org/10.1177/09697330103791 78

[22] Berzoff J, Kita E. Compassion Fatigue and Countertransference: Two Different Concepts. Clin Soc Work J. 2010; 38(3): 341-349. https://doi.org/10.1007/s10615-010-0271-8

[23] Nantsupawat A, Kunaviktikul W, Nantsupawat R, et al. Effects of nurse work environment on job dissatisfaction, burnout, intention to leave. Int Nurs Rev. 2017; 64(1): 91-98. PMid:27882573 https://doi.org/10.1111/inr.12342

[24] Lasalvia A, Bonetto C, Bertani M, et al. Influence of perceived organisational factors on job burnout: survey of community mental health staff. Br J Psychiatry. 2009; 195(6): 537-544. PMid:19949206 https://doi.org/10.1192/bjp.bp.108.060871

[25] Herman J. Trauma and Recovery: The Aftermath of Violence- from Domestic Abuse to Political Terror Basic Books. 2nd ed. Basic Books; 2015.

[26] Advanced social work practice with trauma. 2014. Available from: https://www.cswe.org/.../CSWE.../CSWE.../Traum abrochurefinalforWeb.pdf . aspx

[27] Courtois C, Ford J, eds. Treating Complex Traumatic Stress Disorders: Scientific Foundations and Therapeutic Models. Guilford Press; 2014.

[28] Chandler G. From Traditional Inpatient to Trauma-Informed Treatment: Transferring Control From Staff to Patient. J Am Psychiatr Nurses Assoc. 2008; 14(5): 363-371. PMid:21665779 https: //doi.org/10.1177/1078390308326625

[29] Hall A, McKenna B, Dearie V, et al. Educating emergency department nurses about trauma informed care for people presenting with mental health crisis: a pilot study. BMC Nurs. 2016; 15(1): 21 . PMid:27013926 https://doi.org/10.1186/s12912-016-014 $1-\mathrm{y}$

[30] Muskett C. Trauma-informed care in inpatient mental health settings: a review of the literature. Int J Ment Health Nurs. 2014; 23(1): 51-59. PMid:23363398 https://doi.org/10.1111/inm. 12012

[31] Six Core Strategies to Reduce Seclusion and Restraint Use I National Association of State Mental Health Program Directors. Available from: https://www.nasmhpd.org/content/six-core-str ategies-reduce-seclusion-and-restraint-use Accessed September 18, 2018.

[32] Wilson A, Hutchinson M, Hurley J. Literature review of traumainformed care: Implications for mental health nurses working in acute inpatient settings in Australia. Int J Ment Health Nurs. 2017; 26(4): 326-343. PMid:28480568 https ://doi .org/10.1111/in m. 12344

[33] Stokes Y, Jacob JD, Gifford W, et al. Exploring Nurses' Knowledge and Experiences Related to Trauma-Informed Care. Glob Qual Nurs Res. 2017.

[34] Courtois C, Gold S. The Need for Inclusion of Psychological Trauma in the Professional Curriculum: A Call to Action. Psychol Trauma Theory Res Pract Policy. March 2009.

[35] Isobel S, Edwards C. Using trauma informed care as a nursing model of care in an acute inpatient mental health unit: A practice development process. Int J Ment Health Nurs. 2017; 26(1): 88-94. PMid:27291292 https://doi.org/10.1111/inm. 12236

[36] Wisdom JP, Wenger D, Robertson D, et al. The New York State Office of Mental Health Positive Alternatives to Restraint and Seclusion (PARS) Project. Psychiatr Serv Wash DC. 2015; 66(8): 851-856.
PMid:25930039 https://doi.org/10.1176/appi.ps. 201400 279

[37] Azeem MW, Aujla A, Rammerth M, et al. Effectiveness of Six Core Strategies Based on Trauma Informed Care in Reducing Seclusions and Restraints at a Child and Adolescent Psychiatric Hospital. J Child Adolesc Psychiatr Nurs Off Publ Assoc Child Adolesc Psychiatr Nurses Inc. 2011; 24: 11-15. PMid:21272110 https://doi.org/10.1111/j.1744-6171.2010.00262.x

[38] Bloom SL. Creating Sanctuary: Toward the Evolution of Sane Societies, Revised Edition. Routledge; 2013.

[39] Happell B, Martin T, Pinikahana J. Burnout and job satisfaction: A comparative study of psychiatric nurses from forensic and a mainstream mental health service. Int J Ment Health Nurs. 2003; 12(1): 39-47. PMid:14685958 https://doi.org/10.1046/j.1440-0 $979.2003 .00267 . x$

[40] Hannigan B, Edwards D, Coyle D, et al. Burnout in community mental health nurses: findings from the all-Wales stress study. J Psychiatr Ment Health Nurs. 2000; 7(2): 127-134. https ://doi .org/10.1 $046 / j \cdot 1365-2850 \cdot 2000.00279 \cdot x$

[41] MacKusick CI, Minick P. Why are nurses leaving? Findings from an initial qualitative study on nursing attrition. Medsurg Nurs Off $\mathrm{J}$ Acad Med-Surg Nurses. 2010; 19(6): 335-340.

[42] Taylor B, Barling J. Identifying sources and effects of carer fatigue and burnout for mental health nurses: a qualitative approach. Int $\mathrm{J}$ Ment Health Nurs. 2004; 13(2): 117-125. PMid:15318906 https: // doi.org/10.1111/j.1445-8330.2004.imntaylorb.doc.x

[43] Watts J, Robertson N, Winter R, Leeson D. Evaluation of organisational culture and nurse burnout. Nurs Manag Harrow Lond Engl 1994. 2013; 20(6): 24-29.

[44] Van Bogaert P, Clarke S, Wouters K, et al. Impacts of unit-level nurse practice environment, workload and burnout on nurse-reported outcomes in psychiatric hospitals: a multilevel modelling approach. Int J Nurs Stud. 2013; 50(3): 357-365. PMid:22695484 https: //doi.org/10.1016/j.ijnurstu.2012.05.006

[45] Dhaini SR, Denhaerynck K, Bachnick S, et al. Work schedule flexibility is associated with emotional exhaustion among registered nurses in Swiss hospitals: A cross-sectional study. Int J Nurs Stud. 2018; 82: 99-105. PMid:29626703 https://doi.org/10.1016/j.ijnurs tu.2018.03.019

[46] Hagen J, Knizek BL, Hjelmeland H. Mental Health Nurses' Experiences of Caring for Suicidal Patients in Psychiatric Wards: An Emotional Endeavor. Arch Psychiatr Nurs. 2017; 31(1): 31-37. PMid:28104055 https://doi.org/10.1016/j . apnu. 2016. 07 .018

[47] Baca M. Professional Boundaries and Dual Relationships in Clinical Practice. J Nurse Pract. 2011; 7: 195-200. https://doi .org/10 $.1016 / j$.nurpra. 2010 10.003

[48] Colson DB, Allen JG, Coyne L, et al. An Anatomy of Countertransference: Staff Reactions to Difficult Psychiatric Hospital Patients. Psychiatr Serv. 1986; 37(9): 923-928. https ://doi .org/10.117 6/ps.37.9.923

[49] Evans M. Being driven mad: Towards understanding borderline and other disturbed states of mind through the use of the countertransference. Psychoanal Psychother. 2007; 21: 216-232. https: //doi.org/10.1080/02668730701535578

[50] Berg SH, Rørtveit K, Aase K. Suicidal patients' experiences regarding their safety during psychiatric in-patient care: a systematic review of qualitative studies. BMC Health Serv Res. 2017; 17. PMid:28061899

[51] Cutcliffe JR, Stevenson C, Jackson S, et al. A modified grounded theory study of how psychiatric nurses work with suicidal people. 
Int J Nurs Stud. 2006; 43(7): 791-802. PMid:16289065 https: //doi.org/10.1016/j.ijnurstu.2005.09.001

[52] Lotan G, Tanay G, Bernstein A. Mindfulness and Distress Tolerance: Relations in a Mindfulness Preventive Intervention. Int J Cogn Ther. 2013; 6(4): 371-385. https://doi.org/10.1521/ijct.2 013.6 .4 .371

[53] Luberto CM, McLeish AC. The effects of a brief mindfulness exercise on state mindfulness and affective outcomes among adult daily smokers. Addict Behav. 2018; 77: 73-80. PMid:28965070 https://doi.org/10.1016/j.addbeh.2017.09.013

[54] Guendelman S, Medeiros S, Rampes H. Mindfulness and Emotion Regulation: Insights from Neurobiological, Psychological, and Clinical Studies. Front Psychol. 2017; 8: 220. PMid:28321194

[55] Linehan MM, Wilks CR. The Course and Evolution of Dialectical Behavior Therapy. Am J Psychother. 2015; 69(2): 97-110.
PMid:26160617 https://doi.org/10.1176/appi.psychothe rapy.2015.69.2.97

[56] Goodman MJ, Schorling JB. A mindfulness course decreases burnout and improves well-being among healthcare providers. Int J Psychiatry Med. 2012; 43(2): 119-128. PMid:22849035 https://doi.org/ 10.2190/PM. 43.2.b

[57] Montero-Marin J, Tops M, Manzanera R, et al. Mindfulness, Resilience, and Burnout Subtypes in Primary Care Physicians: The Possible Mediating Role of Positive and Negative Affect. Front Psychol. $2015 ; 6$

[58] Guillaumie L, Boiral O, Champagne J. A mixed-methods systematic review of the effects of mindfulness on nurses. J Adv Nurs. 2017; 73(5): 1017-1034. PMid:27706912 https://doi.org/10.1111/ jan. 13176 